Voix et Images

volxetimages

\title{
Jean Éthier-Blais et la condition franco-ontarienne
}

\section{Robert Major}

Volume 15, numéro 3 (45), printemps 1990

Gilbert La Rocque

URI : https://id.erudit.org/iderudit/200859ar

DOI : https://doi.org/10.7202/200859ar

Aller au sommaire du numéro

Éditeur(s)

Université du Québec à Montréal

\section{ISSN}

0318-9201 (imprimé)

1705-933X (numérique)

Découvrir la revue

Citer cet article

Major, R. (1990). Jean Éthier-Blais et la condition franco-ontarienne. Voix et Images, 15(3), 438-443. https://doi.org/10.7202/200859ar d'utilisation que vous pouvez consulter en ligne.

https://apropos.erudit.org/fr/usagers/politique-dutilisation/ 
Essai

\section{Jean Éthier-Blais et la condition franco-ontarienne}

\section{par Robert Major, Université d'Ottawa}

Que sait-on, au Québec, de l'Ontario français? Peu de choses, en réalité. Sans doute encore moins aujourd'hui qu'il y a quelques générations, alors que chaque famille québécoise envoyait son contingent de bras vers les mines et les forêts du Nord, ou les manufactures du Sud, et que les liens étaient maintenus par cette consanguinité, à une époque où la famille avait une signification et une réalité. Les liens se sont distendus, de lointains cousins n'intéressent plus, et chaque société évolue maintenant parallèlement. Et, dans le cas du Québec, l'Ontario français ne suscite le plus souvent qu'un intérêt poli, sinon l'indifférence.

Le Montréalais qui s'aviserait de sortir de son île et de filer sur la route de l'Ouest ferait éventuellement escale, dans cette course qui suit de près le trajet des anciens voyageurs (rivière des Outaouais, marécages de Bonfield, lac Nipissing), à Sturgeon-Falls. Cette petite ville de quelques milliers d'habitants, en majorité francophones, est à 600 kilomètres de Montréal; toutefois, elle est beaucoup plus près encore de Sault-Sainte-Marie, la plus connue des quarante-quatre villes qui se sont proclamées unilingues anglaises, de par la volonté de leurs citoyens et de par les bons soins de l'Association for the Preservation of English in Canada. Nous sommes en Ontario.

C'est à Sturgeon-Falls qu'est né, il y a quelque soixante ans, Jean Éthier-Blais. Ontarien de naissance, Québécois d'adoption: écrivain québécois. Écrivain après avoir été d'abord critique littéraire, et l'un des plus importants, car il fut parmi les premiers, au début des années soixante, à parler d'œuvres québécoises et de littérature québécoise comme si cela allait de soi: sans ménagements et sans condescendance, abordant les œuvres comme autant de médiatrices valables de ses propres interrogations, les jaugeant à leur propre aune et à la sienne. Puis le critique a accouché de l'écrivain: nouvelliste, poète, romancier, essayiste, mémorialiste, dont l'œuvre se déploie chaque jour davantage, et dans de multiples directions.

Sans doute Jean Éthier-Blais se sent-il à l'âge des bilans provisoires et des retours interrogateurs sur le parcours sinueux d'une existence; peut-être n'est-ce, au contraire, que goût naturel de se raconter et de relever sa trace, avant qu'elle ne s'efface, pour la fixer en 
mémoire: dans la sienne ou celle des autres. On vieillit, les témoins disparaissent, le temps recouvre de sa cendre ce qui a déjà palpité: ne reste que le support aléatoire de l'écriture pour montrer que l'on a vécu... Quoi qu'il en soit de ses motivations, Jean Éthier-Blais vient de nous livrer un très beau livre de souvenirs, merveilleusement écrit, d'une sensibilité frémissante et d'une passion contenue: Fragments d'une enfance ${ }^{1}$.

L'œuvre raconte les douze premières années de sa vie dans cette petite ville du moyen-nord de l'Ontario. Sans doute d'autres volumes s'ajouteront-ils: ainsi celui-ci appelle tout naturellement une suite, consacrée aux années de collège à Sudbury, sur lesquelles il ouvre le rideau. Maỉs même sans suite, cette œuvre constitue déjà un apport important au genre de l'essai autobiographique et une pièce maîtresse de la littérature franco-ontarienne. Cette œuvre appartient à la littérature intime, certes; mais elle constitue aussi une contribution majeure à la réflexion sur la condition franco-ontarienne et ses liens avec la québécité. C'est à cette condition franco-ontarienne que je voudrais m'attarder, mais non sans avoir signalé d'abord quelques aspects de cette autobiographie fragmentée.

Car ce livre de souvenirs est une remarquable réussite. La conscience aiguë du temps qui fuit est tempérée par le regard amusé d'un observateur sagace; l'angoisse devant la fragilité de la vie et des liens qui nous unissent aux êtres les plus chers est atténuée par l'intérêt constant pour la diversité infinie du spectacle humain; la nostalgie et l'attendrissement ressentis à l'évocation du passé sont équilibrés par la conviction intime que chacun vit sa vie dans la plus essentielle solitude et que ce passé, tout en étant révolu à jamais, vit néanmoins dans la conscience des vivants et peut se transmettre et revivre, chaud et vibrant, par la voie de l'écriture. Je tiens d'elle, dira le narrateur de sa mère, de ressentir avec violence la réalité suivante: tous les hommes naissent dans le malheur, et insatisfaits. (p. 113) Et pourtant, cette œuvre regorge de bonheur, du bonheur de l'enfant gâté, intelligent et sensible, dans une famille unie, agréable, chantante et remuante, diverse, aux ruades multiples (p. 126). Bonheur sur fond de malheur existentiel: ambiguïté et mystère de la vie. Évoquant son premier souvenir, le narrateur constate:

Je suis dans un panier d'osier. [...] Nous descendons un escalier, en sorte que mon panier n'est ni à l'horizontale, ni à la verticale. Je vois déjà le monde de travers. Il se présente à moi de façon ambiguë. Je consacrerai ma vie à rétablir l'équilibre de cette vision. (p. 17)

Rétablir l'équilibre. Livre d'une quête, donc: celle du passé; celle du sens; celle de la ligne d'un destin. Il s'agit, en somme, et pour couper court, d'un livre profondément humain, et d'un livre de sagesse. 
Il est donc placé, comme il se doit, sous le signe de la mort, seul sujet valable de nos réflexions. Mort du père, lorsque le narrateur a huit ans, mort qui le laisse inachevé et qu'il ne pardonne pas; mort de la mère, douze ans plus tard, à laquelle il était profondément attaché, et qui le prive de sa seule interlocutrice. Mais ces morts sont inséparables de la vie. Dès les premières pages, un voisin se tranche la gorge, une autre sombre dans une douce folie, une troisième se pend dans un placard. Pendant ce temps, toutefois, le narrateur naît à la vie, hurlant et rouspétant, révolté par la stérilité du sein maternel, puis finalement repu. Autour de lui, graviteront bientôt les autres membres de la famille, frères et sœurs (il est le dixième enfant, le huitième survivant), oncles, tantes et grand-mère, voisins et amis, tous bien campés, à la fois fortement individualisés et typiques, proches du mythe, donnant à cette geste familiale les prolongements d'une mythologie. Voici le père: Pour Noël, mon père revint de ses forêts, entouré de ses hommes ainsi qu'Agamemnon, sûr de lui et de l'autorité de son peu de paroles. (p. 10) Voici la mère, leitmotiv du livre, memoriæ matris dilectissimæ sacrum. Dans la même veine, l'essaim des sœurs aînées et de leurs amies évoquera tout naturellement l'enchantement d'Ulysse devant Nausicaa; la grand-mère, crochetant, son petit-fils à ses pieds, dictera une réflexion sur le temps et l'éternité, le fil des Parques et la chambre de Pythagore; et le lac, le superbe lac Nipissing, présence royale et impérieuse, sera associé à la mer devant Trézène et à la plage sur laquelle s'exerça et mourut Hippolyte.

Car l'espace occupe une place aussi importante que les personnes dans cette relation. La maison, au premier chef, vaste, animée, mais recelant ses lieux de retraite et de solitude; ainsi, comment ne pas déplorer que dans les boîtes écrasées qui tiennent présentement lieu de maisons, on ne trouve plus de greniers, lorsqu'on constate l'importance de ce lieu dans la genèse d'une vocation comme celle-ci: sur ce plan, Jean Éthier-Blais rejoint la Christine de Rue Deschambault. Après la maison, omniprésente, et à laquelle le cerveau du narrateur en viendra à ressembler avec le temps (p. 96), se présentent la rue, le cimetière, le lac, dont la présence se fait partout sentir, et la route, qui mène essentiellement à Ottawa: pour la visite de la parenté, pour les séjours d'étude des aînés, pour le triomphe du concours provincial de français, sur lequel se clôt le récit.

Mais si la route conduit à Ottawa, c'est surtout parce que cette ville est le prolongement naturel de Sturgeon-Falls et la capitale des FrancoOntariens. Car l'Ontario français a sa capitale, comme il a son histoire, ses héros, ses vilains et ses monstres, ses moments d'exaltation et de passion dans une morne guerre de résistance sans illusions. Il a sa sensibilité et son identité, surtout, et jamais je n'ai lu de pages aussi justes sur la condition franco-ontarienne et sur la lente agonie de l'Ontario français: la grandeur de ses luttes obscures, l'humiliation 
quotidienne qui est son lot, les traitrises constantes et l'incompréhension dont il est victime, la lucidité et le courage de ses classes instruites:

Nous étions partagés, ni $d u$ Québec, bien que nos racines immédiates s'y trouvassent, ni Ontariens à part entière; ni Canadiens, puisque le sens de ce mot changeait, ne désignant plus les Canadiens français, et eux seuls, ne désignant pas encore les Canadiens anglais, et eux seuls. Nous avions reçu les limbes en partage et n'y étions pas heureux. [...] Nous étions triplement minoritaires; au Canada, comme appartenant à la nation conquise; en Ontario, à titre d'immigrants français en forteresse anglaise; au Québec, lorsque, par hasard, nous y retournions, cousins déjà lointains et sans doute devenus orangistes. En somme, nous étions de tous côtés, cernés par ces charmantes jumelles, l'ignorance et la bêtise. (p. 116, 125)

Le Franco-Ontarien seul peut parler de l'Anglais et du Québécois, pourrait-on dire, en parodiant Sartre, car lui seul connaît intimement l'un et l'autre, leur étant indissolublement lié, et victime des deux. De l'Anglais d'abord:

$A u$ sens strict, nous étions des humiliés et des offensés. Le racisme canadien-anglais, la superbe naturelle aux Anglosaxons lorsqu'ils ont le haut du pavé, nous en étions les victimes à l'échine souple [...] Nous étions en butte à la haine, à la hargne de la majorité ontarienne, à son besoin d'unité culturelle et linguistique. Nous savions qu'elle y mettrait le temps, mais que le jour viendrait où notre château de cartes s'écroulerait. (p. 115)

Il faut, par exemple, lire la merveilleuse description des Orangistes et de leur défilé annuel pour comprendre la sourde menace qu'une telle manifestation pouvait incarner pour les FrancoOntariens. Sous le folklore et les costumes loufoques, l'Anglais affirmait sa victoire et sa puissance. Les papistes français avaient intérêt à comprendre; et ils comprenaient:

Nous devinions que, derrière ces minables, c'était une majorité haineuse, hypocritement, qui se cachait et qui, à l'abri des circonstances, n'hésiterait pas à agir contre nous. [...] Nous connaissions leur puissance... (p. 83-84)

Mais même quand cette hostilité s'affirme moins bruyamment, elle est à l'œuvre et le Franco-Ontarien sait que chaque année, il aura à payer son tribut à l'assimilation sournoise; la machine assimilatrice fonctionne à plein, pétrie de souveraine bonne conscience de la part de l'assimilant, et d'inconscience chez l'assimilé.

La technique anglaise d'appropriation, je l'ai connue depuis. Elle ressemble à celle des nécrophores. Elle travaille par en- 
dessous, douée de patience. Peu à peu, le vide s'approfondit sous vous, votre sépulture s'élargit, vous vous enfoncez sans vous en rendre compte, dans un trou où vous disparaissez. (p. 88-89)

Et le Québec, devant ce génocide en douce? Indifférent, ignorant, n'ayant cure de ce qui lui semblait obscures échauffourées sur ses marches lointaines, ou permettant que ses petits politiciens s'en servent pour faire carrière, prêts à trahir à la première occasion. Qu'importait au Québec ces Québécois de la diaspora, malgré l'attachement de ces derniers à leur lieu d'origine, véritable mère patrie pour eux. Les Franco-Ontariens savaient donc qu'ils ne pouvaient compter sur les Québécois, qu'ils auraient à faire leur lutte seuls, que l'ignorance du Québec scellerait éventuellement son propre sort. Mais qu'auparavant ils seraient engloutis.

Ainsi se constitue une sensibilité propre aux Franco-Ontariens, ou du moins à leurs élites. Attachement fervent à la langue, combativité constamment aux aguets, connaissance de l'histoire et sens de la mesure, méfiance à l'égard de l'épiscopat catholique, art du compromis et de la guerre d'usure, conscience douloureuse de l'inévitable mais volonté de ne pas flancher pour autant, par fidélité et par fierté. Humiliées, offensées, victimes de brimades quotidiennes et angoissées par l'hécatombe linguistique dont elles étaient à même de constater l'étendue, souvent au sein de leurs propres familles, ces élites luttaient néanmoins avec un courage que ne sauraient même soupçonner l'ensemble des Québécois, encore moins égaler. Comment s'étonner alors que Jean Éthier-Blais, remémorant son enfance, laisse percer à l'occasion son amertume à l'égard de sa patrie d'élection, si aveugle et si insouciante, si indifférente devant cette guerre des tranchées:

Les grandes querelles racistes, une véritable guerre, qui mirent aux prises en Ontario la minorité française et la majorité anglaise, autour de l'école et de l'enseignement du français, n'apparurent trop souvent aux Québécois que comme un épisode dérisoire et lointain. Nous méprisions cette faiblesse et cette absence d'éducation historique. À cet égard, les Québécois, dans leur ensemble, sont tout aussi incultes aujourd'hui qu'ils l'étaient alors. (p. 77)

Car cela est aussi constitutif de la mentalité franco-ontarienne: une certaine distance critique à l'égard du Québec, un certain cynisme aussi devant sa rhétorique si abstraite, un certain désabusement, frôlant.l'ironie, devant ses promesses non tenues. Distance exacerbée par une personnalité bien tranchée dans le cas de Jean Éthier-Blais, et qui lui a valu des inimitiés:

On me reproche aujourd'hui, dans certains milieux, de n'être pas un "vrai Québécois". C'est comme si un Français de 1900 avait accusé Barrès de n'être pas un vrai Français. (p. 77) 
Mais comment pouvait-il en être autrement? Ayant connu le front pendant son enfance, et son coût humain, comment pouvait-il partager le nombrilisme de ses compatriotes québécois. Ceux qu'on appelle aujourd'hui les Franco-Ontariens, et dont je suis par mes origines, sont combatifs et sans illusions (p. 77), dit-il. Y compris sur leur patrie d'élection, le Québec, qui était la patrie réelle des parents ou des grands-parents, et à laquelle quelques-uns reviennent, lucides comme d'anciens combattants, imperméables à la sensiblerie et à une certaine rhétorique. Liberté d'esprit qu'on leur pardonne difficilement.

Même si elle cache mal un amour ardent du pays. C'est donc avec raison qu'Éthier-Blais évoque Barrès; mais il faudrait alors imaginer un Barrès souffrant du pays à naître:

Peut-être, avant de mourir, aurai-je trouvé cette patrie dont, enfant, je ressentais l'absence, cette patrie qui ne m'a jamais protégé. J'ai vécu toute ma vie dans ce pourissoir au creux duquel moi et les miens cherchons à nous lover, à nous faire petits, à disparaître même, pour survivre. (p. 89)

Un Barrès, en somme, qui reprendrait le cri pathétique de Villon dans son épitaphe: Oncques de terre n'eut sillon. (p. 91)

Voilà l'épitaphe tragique des Franco-Ontariens, et l'annonce du destin probable des Québécois. Voilà pourquoi ceux-ci ont intérêt à lire ce remarquable livre de souvenirs, œuvre superbe, tendre reposoir d'amour filial mais aussi, et simultanément, cri d'alarme pour ceux qui ont des oreilles. CEuvre de fidélité dans tous les sens du mot.

1 Jean Éthier-Blais, Fragments d'une enfance, Montréal, Leméac, 1989, 179 p. (Vies et mémoires). 